\title{
El caballero de EI Macalón (Nerpio, Albacete). La emergencia de las aristocracias ibéricas y sus nuevas formas de representación
}

\section{The rider from El Macalón (Nerpio, Albacete). The emergence of the Iberian aristocracies and their new display channels}

Iván Fumadó Ortega

FECYT - Zentrale des Deutschen Archäologischen Instituts Berlin

i.fumado.ortega@gmail.com

Recibido 24/02/2014

Aceptado 11/07/2014

\section{Resumen}

Se estudia una marca anfórica procedente de las excavaciones de García Guinea realizadas en El Macalón (Nerpio, Albacete). Tras un análisis formal e iconográfico de la imagen estampillada, se exploran las implicaciones sociopolíticas que pueden desprenderse del uso, quizá experimental, del singular tampón responsable de este sello. El caballero de El Macalón no ha sido hasta ahora puesto en relación con el resto de representaciones ibéricas de jinetes, pero éste reúne estilos y motivos mediterráneos en una mezcla ecléctica que será recurrente en el arte ibérico posterior. Las características del sello y de la imagen elegida son interpretados aquí como un acto de comunicación innovador en el contexto histórico del Alto Segura del siglo VI a.C. Ello permite tomar al caballero de El Macalón como una de las primeras evidencias de las nuevas prácticas de control del comercio, de reproducción y promoción de estatus y, en definitiva, de representación simbólica adoptadas por las aristocracias ibéricas del Hierro Antiguo.

Palabras clave: Ánforas estampilladas, iconografía ecuestre, aristocracias emergentes, jinetes protohistóricos, fenicio-púnico, ibérico.

\begin{abstract}
An stamped amphoric fragment from the García Guinea's ancient excavations at El Macalón (Nerpio, Albacete) will be examined. A formal and an iconographical study of the stamped image will be followed by some considerations about the sociopolitical implications of the use, maybe experimental, of this uncommon punch. The rider of the El Macalón was not till now put in relation with other lberian representation of riders. But it shows an original, eclectic mix of Mediterranean motives and styles, that will be successful in the later lberian art. The characteristics of both the punch and the selected image are interpreted as an innovative act of communication in the historical context of the Upper Segura Valley during the 6th century BC. That point of view allows to take the rider of the El Macalón as one of the earliest evidences of the new practices of commerce control, status reproduction and promotion, and symbolic representation displayed by the Iberian aristocracies during the First Iron Age.
\end{abstract}

Key words: Stamped amphorae, Equestrian iconography, new aristocracies, Phoenician-Punics, Iberians, Protohistoric riders. 


\section{INTRODUCCIÓN ${ }^{1}$}

Este artículo retoma un fragmento cerámico publicado por Miguel Ángel García Guinea (1960, 722-723) procedente de sus excavaciones en El Macalón (Nerpio, Albacete). Tras su hallazgo, la pieza fue incluida en el catálogo de marcas y epígrafes de Consuelo Mata y Lucía Soria $(1997,320)$. Se trata de un asa de ánfora que conserva, en un segmento de la panza, un particular sello figurado, cuya forma, imagen y función permiten reflexionar sobre las transformaciones protagonizadas por las sociedades del sureste peninsular durante el Hierro Antiguo.

Este periodo, junto al del Bronce Final que le precede, puede considerarse como uno de los momentos más interesantes de la Antigüedad en la Península Ibérica, pues fue entonces cuando se introdujeron en este territorio nuevas tecnologías, como el torno cerámico o los hornos capaces de fundir hierro, nuevas herramientas y nuevas especies vegetales y animales. Estos cambios materiales y tecnológicos hicieron posible el desarrollo de nuevas formas de vida en el marco de los procesos formativos del heterogéneo mosaico de sociedades aristocráticas que la Arqueología moderna ha agrupado bajo el etnónimo ibéricas (Ruiz, Bellón y Sánchez, 2008).

La investigación de la Protohistoria peninsular ha adolecido tradicionalmente de una excesiva dicotomía entre perspectivas globales y locales. Las primeras se han centrado en el fenómeno de la colonización con especial atención a las poblaciones exógenas, mientras que las segundas, en las poblaciones indígenas. Sin embargo, ambas perspectivas no sólo son compatibles, sino también complementarias y, de hecho, dicha dicotomía es más un producto historiográfico que histórico.

El tema del contacto cultural y el de las identidades colectivas, indisociables el uno del otro, han sido ampliamente tratados y lo siguen siendo en los últimos años. No obstante se mantiene un cierto desequilibrio entre la atención que se presta a los yacimientos costeros frente a la que reciben las zonas interiores. Dicho desequilibrio, heredado de la práctica arqueológica de décadas anteriores, es comprensible por la mayor densidad de elementos arqueológicos que se pueden hallar en las áreas próximas al mar. Sin embargo, regiones con menor densidad en este sentido también pueden

1 Este artículo ha sido pensado y redactado mientras disfrutaba de un contrato en la FECYT (2011-2013) para investigar en la sede central de Berlín del Instituto Arqueológico Alemán. El contrato ha sido financiado gracias a las Ayudas a la Movilidad Posdoctoral del Ministerio de Educación convocadas en 2009. Quiero agradecer al Museo de Albacete y, especialmente, a su directora Rubí Sanz Gamo, la atención y facilidades recibidas para consultar la pieza, en el marco del proyecto "Iberos. Aplicaciones del e-learning al patrimonio arqueológico" (FCT-10-1216) dirigido por Susana González Reyero y financiado también por la FECYT. Igualmente agradezco a Ricardo Olmos Romera, ofrecer las características necesarias para esclarecer algunas de las más importantes cuestiones de la Protohistoria peninsular.

En las siguientes páginas, que quieren ser un ejemplo de ello, se introducirán las particularidades del territorio en el que se inscribe el yacimiento. A continuación se presentará el contexto arqueológico en el que apareció el fragmento cerámico estudiado y se describirá formalmente el sello que nos ocupa. Finalmente, antes de pasar a las conclusiones, se reflexionará sobre la imagen que éste presenta y la función o funciones que pudo desempeñar en su contexto histórico.

\section{TERRITORIOS DE FRONTERA Y FRONTERAS TERRITO- RIALES: UNA ENCRUCIJADA EN EL INTERIOR DE LA PenínSula IbÉricA}

La zona del Nerpio es una región montañosa que separa tanto el Alto Guadalquivir de las llanuras manchegas, como el interior de la Meseta de los abundantes recursos mineros y agrícolas murcianos. Este territorio, en donde se encuentran actualmente los límites entre las Comunidades Autónomas de Murcia, Castilla-La Mancha y Andalucía, ha sido históricamente una zona de frontera. Aquí encontramos, entre la cuenca del Alto Segura, la del Alto Guadalquivir y las Sierras de Cazorla, Segura y La Sagra, los actuales límites de tres comunidades autónomas y cinco provincias. El mismo territorio albergó la confluencia en el s. XI de las taifas de Denia, Murcia, Almería y Granada (Martos, 2009), así como las zonas de contacto, algo más al oeste, entre los Conventus Carthaginensis, Astigitanus y Cordubensis de época augustea (Plácido Suárez, 2009) (fig. 1). Se ha propuesto que estas últimas divisiones podrían reflejar una situación preexistente a la Segunda Guerra Púnica (Ruiz y Molinos, 2009) ${ }^{2}$.

Así pues, esta región del sureste peninsular se ha mostrado particularmente adecuada a lo largo de la Historia para la ubicación en ella de los límites del territorio controlado desde los diferentes centros políticos que se han situado a su alrededor. Es, por ello, una zona de frontera.

De esta zona montañosa proceden un buen número de manifestaciones escultóricas del periodo ibérico,

José Ángel Zamora López, Fernando Quesada Sanz, Eduardo Ferrer Albelda, María Cruz Marín Ceballos, Susana González Reyero, Christoph Uehlinger, Marco Fabbri y Alfredo Mederos Martín la amabilidad con la que respondieron a mis preguntas.

2 Si bien ambos autores se centran en el estudio de una zona de frontera ubicada sensiblemente más al oeste de la que aquí nos ocupa, y que separaría los territorios a ambos lados del río Guadalbullón, adoptado por la reforma de Augusto para separar los Conventus Astigitanus y Cordubensis, estas reflexiones podrían ser extensibles a otros territorios del sur y sureste peninsular ( $c f$. Adroher 2008). 


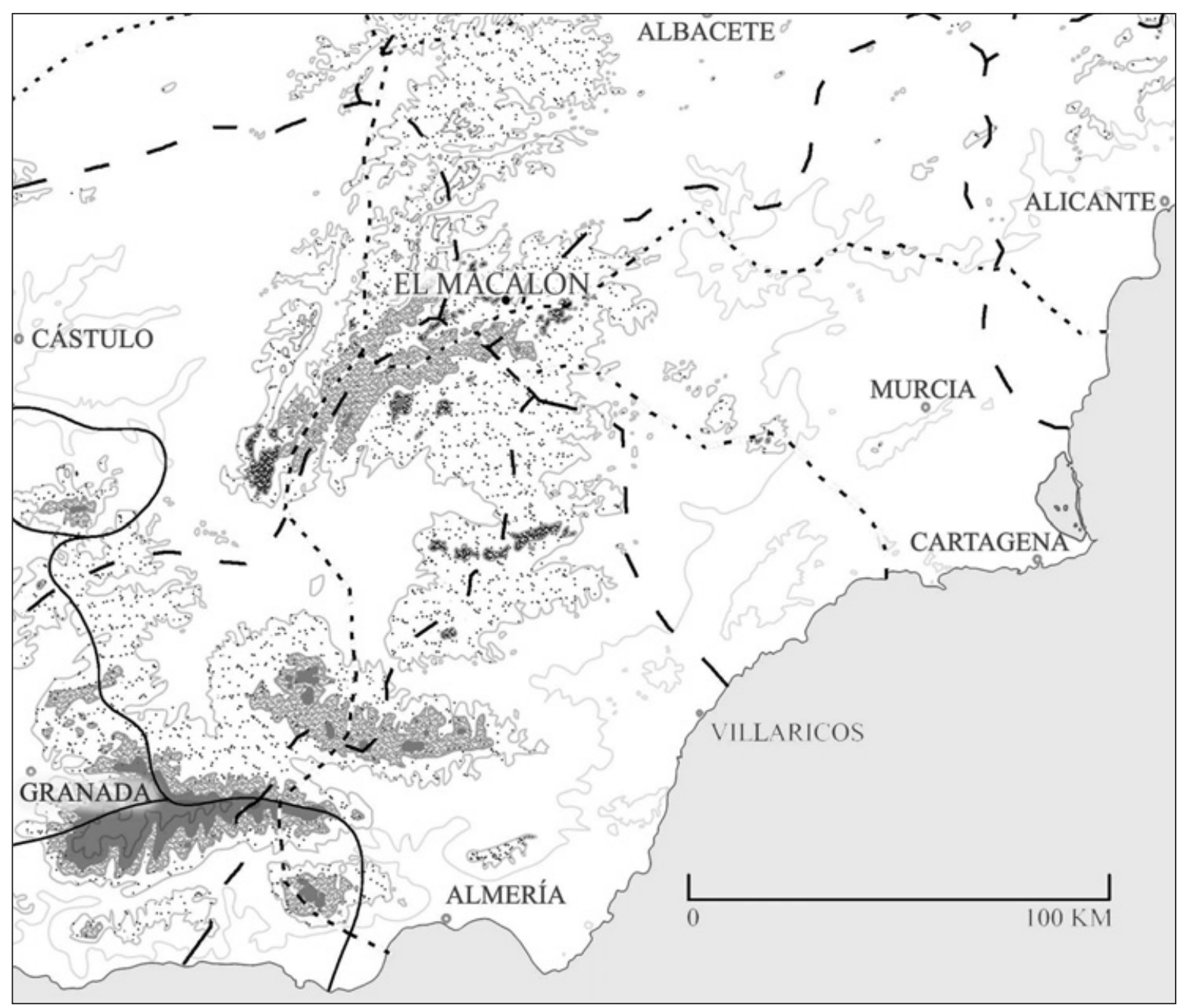

Figura 1. Mapa del Sureste de la Península Ibérica en el que se aprecian tres delimitaciones territoriales: Con el trazo continuo se indican los límites de los Conventus Carthaginensis, Astigitanus y Cordubensis de época de Augusto; con el trazo punteado, los límites de las taifas de Denia, Murcia, Almería y Granada del s. XI; con el trazo discontinuo el de las actuales provincias de Alicante, Murcia, Almería, Granada, Jaén, Ciudad Real y Albacete. Elaborado por el autor.

e.g. los fragmentos de Bienservida-Villarrodrigo, del Cercado de Galera (Liétor), de Haches (Bogarra), de El Macalón (Nerpio) o de Jutia (Yeste), todos ellos al suroeste de la provincia de Albacete (Chapa, 1985; id. 2009). Algunas de estas esculturas pueden contarse entre las más precoces del arte ibérico. Ello confirma el interés del área en cuestión para el estudio de la construcción de discursos complejos de autorrepresentación política y legitimación territorial entre las sociedades protohistóricas de la Península Ibérica.

\section{UNA MARCA ANFÓRICA SINGULAR PROCEDENTE DE El Macalón}

El Macalón es uno de los yacimientos más interesantes de esta zona montañosa. Excavado en los años 60 del siglo XX por Miguel Ánguel García Guinea (1960; García Guinea y San Miguel Ruiz, 1964), no ha recibido desde entonces más que atención parcial en pequeñas excavaciones y estudios de materiales (Soria, 1999; Pellicer, 1999; Blech y Ruano, 1999). El asentamiento se encuentra en un cerro amesetado a $1250 \mathrm{~m}$ de altitud, elevado unos $100 \mathrm{~m}$ sobre el territorio circundante. Se halla en el margen del río Taibilla que, 30 $\mathrm{km}$ más al norte, desemboca en el río Segura frente al yacimiento de Peñarrubia (Elche de la Sierra, Albacete). El cerro presenta una superficie aproximada de 8 ha, de las que tan sólo 4 ha se encuentran en el interior de un recinto amurallado. Un potente talud cubierto por una gran concentración de mampuestos medianos y grandes delata el trazado de la muralla a lo largo de unos $200 \mathrm{~m}$ de longitud. Dicha muralla y los farallones que rodean al cerro conforman una posición defensiva privilegiada para la construcción de un asentamiento humano estable (Soria, 2000, 266).

Al contar sólo con excavaciones antiguas o no publicadas es difícil reconstruir con detalle la secuencia estratigráfica de El Macalón. Sin embargo, a través de los estudios anteriormente mencionados se ha podido identificar en el yacimiento la existencia de un estrato, el más profundo, compuesto exclusivamente por cerámicas realizadas a mano, tanto de factura grosera como más cuidadas, con formas típicas del Bronce 
Final Reciente entre las que se cuentan vasos con cordones, mamelones, impresiones digitales y bordes dentados para los individuos más comunes y superficies muy bruñidas o espatuladas y carenas altas para los más cuidados. Estos materiales pueden encuadrarse en una cronología aproximada del s. VIII a.C. (Pellicer, 1999, 286 fig. 6), que podemos asumir como fecha válida para el momento de fundación del asentamiento.

El material cerámico más moderno allí recuperado está compuesto por cerámicas ibéricas oxidantes comunes, con abundancia de las pintadas con bandas finas y círculos concéntricos monócromos en rojo o negro. Este dato, unido a la datación del registro anfórico ( $v$. infra) han motivado propuestas para la fecha de abandono del yacimiento de principios del s. IV a.C (Pellicer, 1999, 285-286) o finales del s. V a.C. (Soria, 1999, 296). La total ausencia de cerámicas de barniz negro, ya sean campanienses o griegas, parece confirmar este marco cronológico. Nuevos sondeos estratigráficos o la publicación de los realizados en los años 80 permitirían concretar las fechas de fundación y abandono del yacimiento.
Además de las puntas de flecha de bronce que dieron nombre a su tipología, uno de los objetos arqueológicos más relevantes aquí recuperados es el asa sellada, publicada ya por García Guinea (1960, 722-723), objeto ahora de un nuevo estudio (fig. 2). La pieza procede del sondeo bautizado como la Habitación de las Cerámicas. El asa fue hallada en la parte superior del estrato II. Éste estaba compuesto principalmente por las ánforas más antiguas del área del Estrecho de Gibraltar, tipo T.10.1.2.1, y por otras, más modernas, de los tipos T.1.3.1.1, T.1.3.2.4. y T.1.2.1.3 (Pellicer, 1999, 283-284), con una cronología de mediados del s. VI a.C. a mediados del s. V a.C., procedentes del sureste peninsular, alguna de ellas de la ciudad de Baria y su entorno. También había otros ejemplares, en menor número, del tipo T.1.3.2.1 del Mediterráneo central de finales del s. VI a.C. (Ramón, 1995, 168-173), así como algunas ánforas ibéricas de los primeros tipos (Cela, 2006), muy similares a los modelos fenicios (Bonet y Mata, 2008).

Este estrato aparecía sellado por el derrumbe de una serie de muros de adobe y piedra. Dado el gran tamaño de muchos de los galbos y su disposición, los

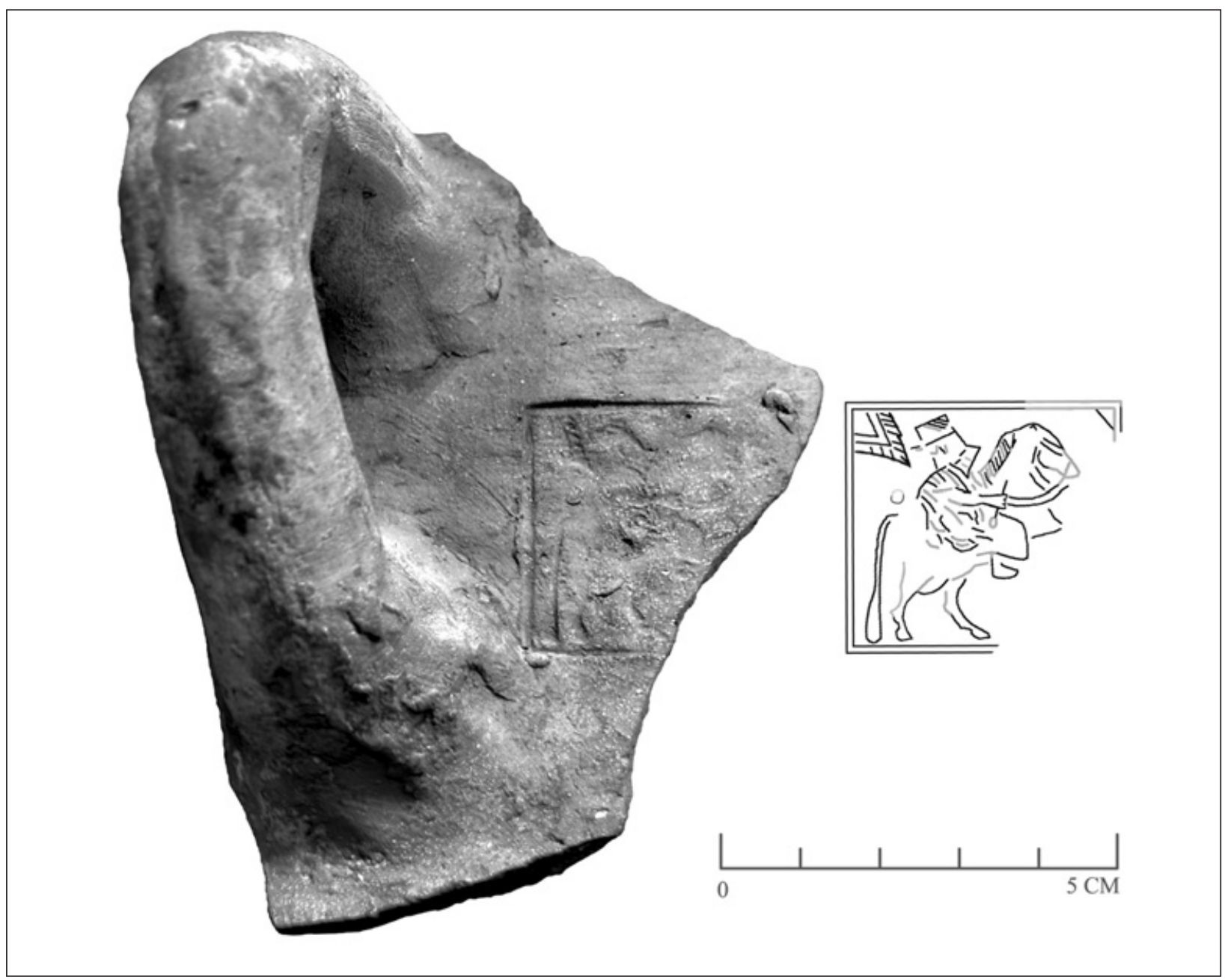

Figura 2. Fotografía del galbo anfórico hallado en El Macalón y dibujo de la estampilla en él aplicada. Elaborada por el autor. 
excavadores concluyeron que las ánforas se hallaban en posición primaria y que se rompieron a causa del desmoronamiento del edificio. Varios de estos contenedores presentaban marcas estampilladas o incisas en el asa o alrededores. La abundancia de ánforas que presenta la Habitación de las Cerámicas y su proximidad a la muralla permiten plantear la hipótesis de que el edificio fuese un almacén. Lamentablemente los límites de la excavación no alcanzaron los de la propia estructura arquitectónica, por lo que carecemos de una planta de conjunto de la construcción.

\section{FORMA: ¿UNA MARCA MÁs?}

Ésta y otras ánforas estampilladas aparecidas en la Península Ibérica ya han sido estudiadas con atención. Sin embargo, como resulta evidente en el catálogo de Consuelo Mata y Lucía Soria, el sello que nos ocupa (fig. 2) se distingue del resto por su iconografía y cronología al ser el más antiguo del mencionado catálogo y el único con representación figurativa. Atenderemos en primer lugar, no obstante, a su forma, también particular, que es la del objeto empleado como tampón.

En el galbo de un ánfora ibérica de tipo antiguo, junto al arranque del asa, se aprecia un sello precocción rectangular de $13,3 \mathrm{~cm}^{2}$ de superficie ( 38 por 35 $\mathrm{mm}$ de lado). El rectángulo enmarca una escena figurativa excepcional en un bajorrelieve de poca profundidad. Dicha característica también diferencia esta marca del resto del catálogo, que suelen aparecer en altorrelieve al ser producidas por un tampón apósito. Estos hechos llevaron a las autoras del mencionado catálogo a plantear que se hubiera aplicado aquí un tampón ocasional, no concebido a tal efecto (Mata y Soria, 1997, 320).

Esta característica incrementa la singularidad de la pieza y justifica una pequeña reflexión sobre dicho tampón ocasional. Debió de tratarse de un objeto compacto, sólido, pequeño y ricamente decorado en un ligero altorrelieve. Los candidatos producidos durante el Bronce Final y el Hierro Antiguo con estas características son, en principio, muchos. Una consulta a la colección Prähistorische Bronzefunde invita a descartar, sin embargo, las empuñaduras de espadas y cuchillos, sus hojas, las de las lanzas y otros armamentos, arreos de caballos, engastes de corazas y cinturones, fragmentos de cascos y escudos, piezas de vajilla,

3 Cabe destacar, no obstante, la presencia en el yacimiento de Peña Negra (Crevillent, Alicante), de una plaquita rectangular de bronce datada entre el s. VII a.C. y principios del s. VI a.C., con cartucho rectangular y decoración figurada de un animal que podría interpretarse como un équido. Sus dimensiones, no obstante, parecen ser muy reducidas, próximas al centímetro de lado (González, 1986, 300 fig. 12.5825). Una plaquita de oro que sí presenta dimensiones y forma similares a la empleada para cuñar el ánfora de El Macalón, también con decoración figurada, se encuentra recogida en el cabezas de aguja, etc., pues sus características morfológicas se separan claramente de las del objeto empleado como tampón en el ánfora amortizada en El Macalón. Mucho más probable resulta el uso a tal efecto de plaquitas-colgantes, pendientes, fíbulas, brazaletes e incluso escarabeos, aunque estos últimos, por su habitual morfología de esquinas redondeadas, podrían ser también descartados, incluso los ejemplares fenicios que tratan el tema del guerrero al galope ( $c f$. Boardman, 2003, 88-89 lám. 26).

En la costa siriopalestina y en Egipto se pueden encontrar numerosas plaquitas rectangulares decoradas, tanto en arcilla como en piedra, empleadas para estampillar (Keel, 1995, 88-89). Sin embargo, tanto su iconografía habitual, elevada cronología, y reducidas proporciones (entre 3,5 y 1,2 $\mathrm{cm}^{2}$ de superficie, frente a los 13,3 $\mathrm{cm}^{2}$ del caso de El Macalón), además del hecho de que casi todas han sido realizadas en bajorrelieve (Keel, 2010, 85 n. 95; 91 n. 104; 115 n. 41; 141 n. $97 ; 187$ n. 202) desaconsejan considerar dichas plaquitas-colgantes como posibles tampones. Por su reducido tamaño y sus motivos iconográficos habituales, podemos descartar asimismo los amuletos egiptizantes que aparecen habitualmente en contextos fenicios y púnicos de la Península Ibérica ${ }^{3}$, como en el ajuar de la tumba 5 de la necrópolis de Puente de Noy (Almuñécar, Málaga) (Molina, 1986, 210 fig. 12), por citar un ejemplo.

La morfología del tampón que buscamos tampoco se adecua a la de los marfiles fenicios del Bajo Guadalquivir (Aubet Semmler, 1978; id. 1982). Estos ejemplares de producción fenicia occidental tardía (Aubet, 1980, 75), así como los marfiles de Arslan Tash, Enkomi o Nimrud, más antiguos y de mayor calidad (Winter, 1976), son similares estilísticamente al caballero de El Macalón (v. infra) pero superan con creces los $13 \mathrm{~cm}^{2}$ de superficie ${ }^{4}$.

Las dimensiones y forma de la marca hallada por García Guinea se aproximan más, en cambio, a las de la base de algunos pendientes y colgantes también frecuentes en contextos fenicios y púnicos, como en la necrópolis del Puig des Molins (Velázquez, 2007, 138140 lám. 5-7). Pero también abundaron materiales similares en contextos griegos (Kilian-Dirlmeier, 1979, láms. 11-16 y 51-61) (fig. 3.1-4). Las características intrínsecas de estos objetos, pequeños y llamati-

catálogo de hallazgos protohistóricos de oro en la Península Ibérica, si bien su procedencia es desconocida (Pingel, 1992, lám. 64.15).

4 La mayoría de estos ejemplares tienen dimensiones entre 24 y $126 \mathrm{~cm}^{2}$. También resulta demasiado grande la plaquita de hueso de procedencia etrusca recuperada en la necrópolis del Puig des Molins, de 32 por $66 \mathrm{~mm}$ de lado, en donde una esfinge aparece enmarcada por un cartucho rectangular de $21 \mathrm{~cm}^{2}$ de superficie (Vendrell, 2010, 334 fig. 2). 
vos, les convierten en perfectos candidatos para viajar más allá de su ámbito geográfico de producción. Las posibilidades de que un pendiente de este tipo hubiese servido de tampón ocasional para el ánfora que llegó hasta El Macalón quedan abiertas, si bien su procedencia es, por el momento, imposible de determinar y, evidentemente, no tiene por qué coincidir con el lugar en donde se selló el contenedor.

Más probable es que el tampón ocasional hubiera sido una de las placas centrales de un brazalete decorado. Un ejemplo sobresaliente y bien conocido, fabricado en oro, procede de un ajuar funerario de los ss. VII-VI a.C. de Tharros (Quatrocchi, 1974, 98-99 lám. 10.127). Aunque el motivo decorativo es aquí muy diferente, destacan sus formas y medidas casi idénticas a las del tampón que produjo el sello encontrado por García Guinea: un cartucho rectangular de 37 por 34 $\mathrm{mm}$ de lado enmarcando una escena figurada en leve altorrelieve. Además, el engarce de las placas de la pieza de Tharros se realiza mediante un refinado sistema, que evita la presencia en su superficie de elementos funcionales, remaches o pequeños pernos, como en cambio suele ser habitual en la mayoría de las joyas de este tipo ${ }^{5}$ ( $c f$. Almagro, 1986; Perea, 1991; de la Bandera 2010).

Este breve análisis morfológico no nos conduce hasta la pieza responsable del sello estudiado aquí. Sí nos permite asegurar, en cambio, que se trató de un pequeño objeto ricamente decorado, sólido y probablemente realizado en bronce $\mathrm{u}$ otro metal noble. Podemos descartar, por sus dimensiones, las piezas decoradas con similar detalle en marfil o hueso. El objeto que buscamos, probablemente un colgante o brazalete pequeño y llamativo, entra dentro de una categoría de elementos del ajuar personal susceptible de presentar una alta movilidad geográfica, incluso de gran distancia entre los lugares de fabricación y amortización. Muchos de estos objetos, así como sus fabricantes y quizá también sus portadores, estuvieron en contacto con tradiciones diversas a la propia, procedentes de otras regiones mediterráneas. Así, el objeto responsable de la marca nos alerta sobre su dualidad, local y mediterránea, que también puede deducirse del estudio de los motivos representados y de la escena éstos que componen.

5 Como ejemplo podría tomarse, a pesar de las dudas sobre su autenticidad (Almagro Basch, 1975, 15 nota 78), la plaquita de bronce de Churriana (Málaga): un cuadrado de $35 \mathrm{~mm}$ de lado de bronce y pasta vítrea ricamente decorado con motivos egiptizantes datados en torno al s. VII a.C., que presenta en sus cuatro esquinas una pequeña perforación cuadrada (Marín, 1980, lám. 7 fig. d).

6 Otros tipos procedentes de las islas del Egeo, especialmente en las del sur, también presentan estas plaquitas, con la particularidad de un tamaño más reducido y casi siempre sin decoración, si bien existen algunas notables excepciones ( $c f$. Sapouna-Sakellarakis 1978, 106-107 lám. 44 nn. 1497-1499).

\section{ESTILO: ¿UNA TRAdICIÓN LOCAL?}

La combinación de trazos esquemáticos y realistas en la escena de El Macalón delata un estilo orientalizante. El tocado y la barba del jinete, así como de las crines de su caballo, están representados con trazos rígidos y poligonales mientras que el resto del animal, del mismo modo que la túnica, brazos y piernas del caballero, aparecen con rasgos más delicados, curvilíneos y de mayor realismo. Dicha combinación estilística, como ya se ha mencionado, recuerda a la de los marfiles fenicios del Bajo Guadalquivir: a las escenas presentes en las cucharas con mango decorado de la necrópolis del Acebuchal (Aubet, 1980, 60-62, fig. 11), a las de las placas caladas procedentes del túmulo de Alcantarilla (Aubet, 1980, 70-74 fig. 15) o a las de los peines de marfil del Llanete de los Moros (Montoro, Córdoba) (Martín, 2003), aunque ejemplares similares han sido recuperados en las necrópolis de Cartago (Bisi, 1968) o en el Hereo de Samos (Freyer-Schauenburg, 1966, 104-120). El estilo de la escena de El Macalón es el mismo, a grandes rasgos, que el de las decoraciones de los objetos de marfil, bronce y plata que los fenicios distribuyeron por el todo el Mediterráneo arcaico (Jiménez, 2002; AlmagroGorbea, 2004; Mederos y Ruiz, 2004). Diferente es, por ejemplo, el estilo de la plaquita de El Alberri (Cocentaina, Alicante) que, aunque ha sido propuesta como paralelo por representar a un jinete cazando a su presa, presenta exclusivamente trazos esquemáticos muy rígidos (Abad, Sala y Sánchez, 1993, 56-59).

El contraste entre abstracción y realismo en la marca anfórica estudiada es especialmente evidente por la presencia de un elemento puramente geométrico que aparece en la esquina superior izquierda de la imagen. Este elemento está compuesto por trazos que, combinados con los bordes del cartucho, conforman una serie de polígonos romboidales concéntricos y ligeramente irregulares. Aunque la decoración de las esquinas mediante varias soluciones es muy habitual en todo el Mediterráneo antiguo resulta significativo que los paralelos iconográficos más cercanos de este elemento se hallen en los tipos de fíbulas griegas IV, VII y VIII de Blinkemberg (1926, 87-106 y 128-184). Estos tipos, datados entre finales del s. VIII a.C. y principios del s. VII a.C. (Kilian, 1975, 170-171; Philipp, 1981, 273282), presentan una plaquita ${ }^{6}$ plana y rectangular anexa al extremo del nervio, en cuya superficie se graban escenas figuradas ${ }^{7}$. Las esquinas superiores de estas

7 Aunque algunas de estas plaquitas decoradas presentan dimensiones muy superiores a la estampilla hallada en El Macalón, pudiendo llegar a los $38 \mathrm{~cm}^{2}$ y hasta los $58 \mathrm{~cm}^{2}$ de superficie, también existen ejemplares menores, con 19 $\mathrm{cm}^{2}$ y hasta $9 \mathrm{~cm}^{2}$ de superficie (Kilian, 1975, 160-161 nn. 1873-1884 lám. 61-62; 117-118 n. 1371 lám. 49). El motivo del caballo con decoración geométrica en una de las esquinas superiores aparece en dos fíbulas procedentes de Kainourgion y Philia (Tesalia) y en otras de Tranaga, Olimpia y Delfos (Philipp, 1981, 274 lám. 60 n. 1010; 282 lám. 61 n. 1014). 
plaquitas se rematan con unos trazos geométricos que guardan una gran similitud con los de la estampilla de El Macalón (fig. 3.6 interior y 3.5 exterior). Nótese que uno de estos elementos esquemáticos es casi idéntico al del sello del ánfora ibérica. No obstante, una interpretación concreta del mismo no es posible por el momento, si bien podría tratarse de la esquematización de un cuerpo celeste o sobrenatural.

Vemos así que el estilo de la escena de El Macalón encuentra sus paralelos más estrechos en objetos que circularon por un Mediterráneo arcaico en proceso de expansión y crecientes conexiones interculturales, sin que puedan dichos paralelos reconducirse a una tradición iconográfica bien delimitada y circunscrita a un único ámbito cultural ${ }^{8}$ : el estilo empleado en la figura de El Macalón delata así un eclecticismo, involuntario o no, pero consciente de varias tradiciones iconográficas exógenas a la región del Nerpio. No obstante, como veremos a continuación, esto no debe hacernos infravalorar la importancia del factor local.

\section{COMPOSICIÓN: ¿UNA REPRESENTACIÓN TÍPICA DEL MEDITERRÁNEO TARDOARCAICO?}

La marca anfórica está realizada en un bajorrelieve de escasa profundidad. Ello, sumado a su estado de conservación, no permite una identificación tan precisa de los detalles de la escena como sería deseable. No obstante, además del elemento abstracto, hay otros fácilmente reconocibles.

Del propio caballero se reconoce el tocado, de tipo tiara, frecuente en representaciones procedentes de un abanico geográfico y cronológico muy amplio, e.g. desde la plaquita de marfil procedente del Megiddo del s. XII a.C. hasta los ases neopúnicos malacitanos (fig. 3.11 ), pasando por la estela y la placa cerámica de Yehawmilk (Nunn, 2000, 13-14 lám. I.1-2), ambas procedentes del templo de Baal de la Biblos del s. V a.C., la Estela del Sacerdote (fig. 3.9), procedente de la Cartago de los ss. IV-III a.C. (Bénichou-Safar, 2007, 32 lám. IV.2), o la de Baalyaton (fig. 3.10), de Umm elAwamid, ya en época helenística. La barba, ya mencionada, también recuerda a los modelos orientales, concretamente a los neoasirios que pueden apreciarse,

8 Los tipos mencionados de fíbulas griegas presentan una dispersión concentrada en la Grecia continental, especialmente en Tesalia, así como en ciertas islas del Egeo (Philipp, 1981, 270-286; Sapouna-Sakellarakis, 1978, 106-107) sin que se haya encontrado, sorprendentemente, ningún ejemplar ni en Sicilia ni en el sur de Italia, ni tampoco en la Península Ibérica (Lo Schiavo, 2010). Sin embargo, su habitual presencia en contextos orientalizantes y privilegiados permite pensar que estas fíbulas circularon en puertos y mercados frecuentados por comerciantes y artesanos cuyo radio de acción superó ampliamente el área del Egeo (Kourou, 2008). Dos ejemplares de estos tipos fueron hallados en Tranaga (Tesalia) formando parte de un ajuar funerario del s. VIII a.C. perteneciente a una joven aristócrata de 18 años entre otros lugares, en los palacios de Khorsabad y Nínive (Bär, 1996). Tocado y barba del caballero de El Macalón responden, por tanto, a modelos típicos del mundo levantino y fenicio-púnico.

La pierna y el brazo derecho del jinete son reconocibles. Éste, con una mano ligeramente sobredimensionada, sujeta a la vez las riendas del caballo y un objeto estrecho y alargado (¿un cayado, una vara?). Es difícil, en cambio, describir detalladamente la indumentaria del caballero que parece vestir una especie de túnica.

El animal parece estar en reposo o suave movimiento, pero en ningún caso al galope. En él destaca tanto la larga cola como las crines representadas de forma similar a la barba del jinete, con trazos esquemáticos y rígidos. Se trata, por tanto, de un jinete estático, que no cabalga, no caza y no lucha. Parece como si su acción principal fuera la de exhibirse como tal. Se da así lugar a una escena ecuestre en reposo más particular de lo que parece a primera vista.

Es un hecho conocido que el hombre ha cabalgado desde hace milenios y que, desde entonces, las escenas figuradas de jinetes han sido muy abundantes en todo el Mediterráneo (Drews, 2004 con abundante bibliografía). Tampoco faltan estas representaciones en el mundo fenicio-púnico, de donde esta estampilla parece haber tomado mayores elementos estilísticos ( $v$. supra) y, quizá, también temáticos. Sin embargo, a diferencia del sello de El Macalón, todas las representaciones de jinetes que se conocen en el ámbito cultural fenicio-púnico corresponden a guerreros (Pisano, 1996), la mayoría de ellos al galope ${ }^{9}, e . g$. el del anillo de oro de finales del s. VII a.C. del tesoro de Aliseda (Cáceres) (Almagro-Gorbea, 2005, 63 fig. 1), los que aparecen en los discos cerámicos de las necrópolis de Douïmes en Cartago (Astruc, 1959, lám. IV.1) y de Utica (Cintas, 1951, 54-56 fig. 22), ambos procedentes de ajuares del s. VI a.C., o el jinete del escarabeo del s. IV a.C. de la necrópolis del Puig des Molins de Ibiza (Fernández y Padró, 1982, 154-157 n. 55). Esta actitud guerrera es también la más habitual entre los jinetes arcaicos del área etrusca e itálica. En este área, además, también aparecen caballos en escenas cultuales

(Onasoglou, 1981, 14-22). El ajuar contaba también con (dos brazaletes, 20 anillos, varias agujas, cuentas de collar y dos boles de bronce, uno de los cuales presentaba una inscripción hitita epigráficamente relacionada con Zincirli (Onasoglou, 1981, 49 n. 169; Kourou, 2008, 335-346).

9 Sobre la tradición fenicia, púnica y cartaginesa en la representación de guerreros cabalgando al galope $c f$. Pisano (1996, 922-924) con la bibliografía indicada en sus notas a pie de página. Diversamente a esta tradición, desde principios del s. V a.C. también aparecen representaciones de jinetes estáticos en el Mediterráneo oriental. Para el mundo griego $c f$. Moore (1972) y para el mundo persa $c f$. Gabrielli (2006). 


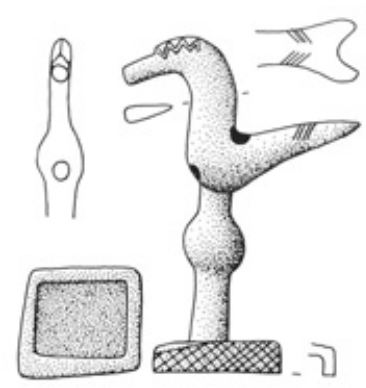

1

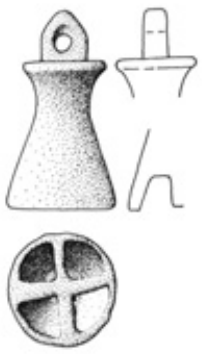

3

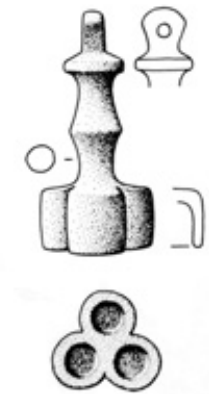

2

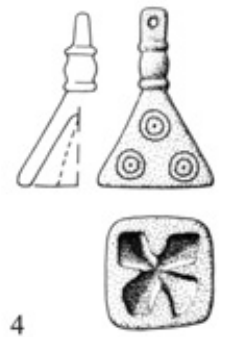

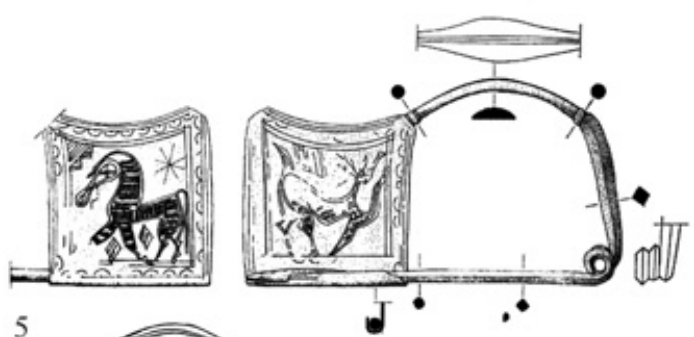

5
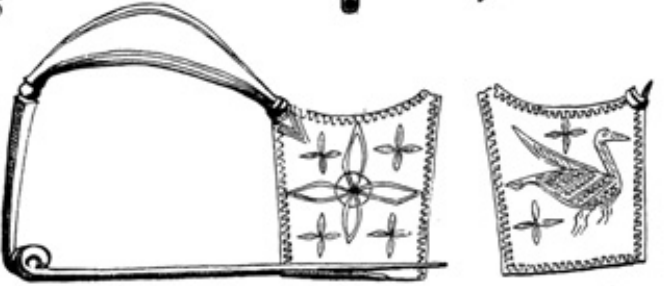

6

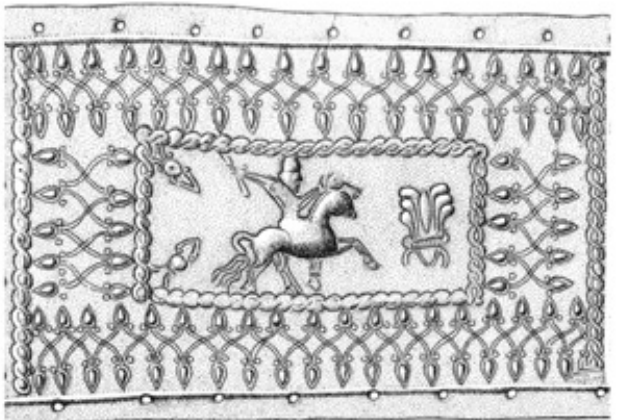

7

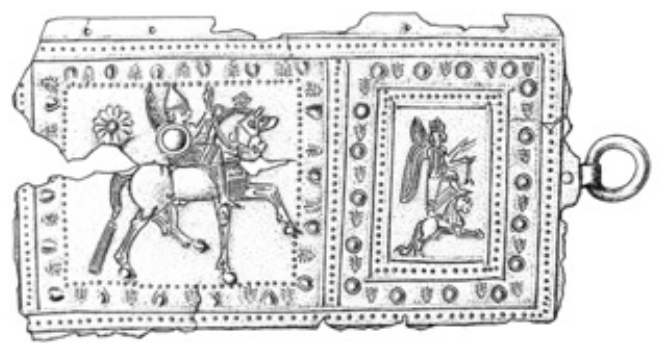

8

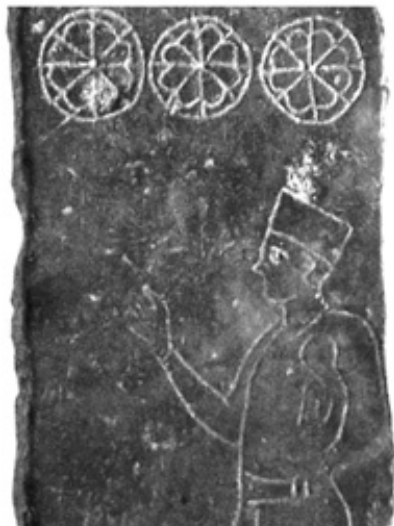

9

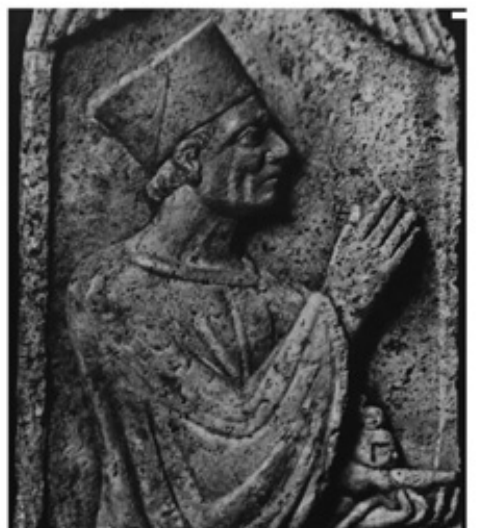

10

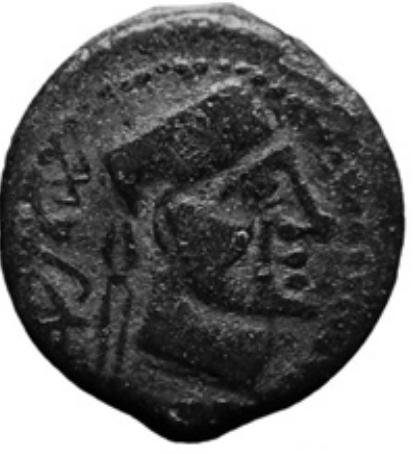

11

Figura 3. 1-4: Pendientes-colgantes procedentes del área de Tesalia (1) y Arcadia (2-4); 5-6: Fíbulas de bronce procedentes de Tranaga (Tesalia) (5) y Tebas (6); Fragmentos en bronce de dos cinturones urarteos, de procedencia desconocida, datados entre mediados del s. IX a.C. y finales del s. VII a.C. El primero de ellos (7) mide 98 por $1270 \mathrm{~mm}$, aunque el recuadro que se aprecia en el detalle mide 21 por $43 \mathrm{~mm}$. La segunda pieza (8) mide 96 por $170 \mathrm{~mm}$ de lado, ocupando el área del jinete una superficie de $44 \mathrm{~cm}^{2}$. En ellos se aprecia una decoración que incluye el tema del guerrero a caballo según unos esquemas plásticos que recuerdan, en dimensiones sensiblemente mayores, a los de nuestra figura 2; 9-11: Representaciones en

las que se aprecia la característica tiara fenicio-púnica con la que se tocan sacerdotes y divinidades: un fragmento de la Estela del Sacerdote (9), un fragmento de la Estela de Baalyaton (10) y un as neopúnico malacitano (11).

Fuentes: 1: Dilian-Kirlmeier, 1979, 1. Lám. 34 n. 1002; 2: Lám. 12 n. 190; 3: Lám. 12 n. 180; 4: Lám. 14. n. 265;

5: Kourou, 2008, 338 fig. 21.3; 6: Blinkemberg, 1926, 173 fig. 205; 7: Kellner, 1991, 64-65 lám. 60-61.238; 8: Kellner, 1991, 57 lám. 50.191; 9: Ribichini, 2004, 257; 10: Parrot, Chébab y Moscati, 2005, 158 fig. 118; 11: Alfaro Asins, 1986.

Figura elaborada por el autor a partir de las fuentes citadas con imágenes no a escala. 
tirando de carros ceremoniales en los que personajes aristocráticos y/o mitológicos, desnudos o semidesnudos, pasean en procesión (Lubtchansky, 2005; Torelli 1997, 87-122). El caballero de El Macalón no puede equipararse a los guerreros púnicos ni participa en una procesión itálica. Sorprendentemente, los paralelos más estrechos (fig. 3.7-8) para la composición general de la escena proceden de la orfebrería urartea (Kellner, 1991, pl. 49.186, 50.191, 61.238, 88.444 y 88.447).

Cabe recordar que en el ámbito ibérico, a diferencia del púnico, sí se desarrollaron escenas de jinetes desarmados, algunos de ellos estáticos. En este sentido destacan, por ejemplo, las esculturas funerarias que coronaban los túmulos de la necrópolis de Los Villares (Hoya Gonzalo, Albacete) (Blánquez, 1996; Sanz y Blánquez, 2011) o el pilar-estela de Coimbra del Barranco Ancho (Jumilla, Murcia) (Izquierdo, 2000, 100-104), manifestaciones que se datan entre los inicios del s. V a.C. y los del s. IV a.C., y a las que se pueden sumar algunas decoraciones cerámicas, más tardías, del Tossal de Sant Miquel (Llíria, Valencia), como las de los dept. 116 y 118 (Bonet, 1995, 265). En estas representaciones no se hace ostentación explícita de la violencia, como sí sucede en el caso de los guerreros al galope fenicio-púnicos o como se aprecia también en alguna de las más antiguas representaciones de caballos que llegaron a la Península Ibérica desde Grecia ${ }^{10}$. En las imágenes ibéricas anteriormente mencionadas el caballo aparece como atributo del jinete. Así en éste se resalta, desde los ejemplos más antiguos (Domínguez, 2005, 225), su riqueza y posición social privilegiada $^{11}$. A estos atributos se añadieron además, en escenas más modernas, su habilidad y destreza (Aranegui, 1997, 73). Quizá este hecho esté relacionado con la evolución del rol del caballo en el campo de batalla ibérico en donde, al menos durante el periodo Ibérico Antiguo, fue empleado tan sólo como transporte para los infantes (que tuvieran la suerte de pertenecer a la aristocracia). En una evolución similar a la documentada en la historia militar griega, sólo en periodos posteriores se formaría un cuerpo de caballería destinado a combatir montado (Quesada, 1997). El caballo como símbolo de estatus social, más que como factor de superioridad militar, es como aparece de hecho en el complejo escultórico erigido a principios del s. V a.C. en la necrópolis del Cerrillo Blanco (Porcuna, Jaén).

${ }^{10}$ Como en el caso de la copa Droop hallada en Cabezo del Tío Pío (Archena, Murcia), del tercer cuarto del s. VI a.C., en la que se apreciaba un auriga en combate. Sin embargo, no debemos obviar que también en Grecia existió una relación entre la aristocracia y el caballo que iba más allá de su función militar cambiante y que se hizo especialmente patente en el ámbito funerario, como queda de manifiesto ya desde los enterramientos del heroon de Lefkandí (Popham et al.,
De este modo, vemos que la escena representada en la marca anfórica de El Macalón, rica en elementos mediterráneos, también contiene matices que la distinguen de la mayoría de escenas de jinetes producidas en otras geografías durante el periodo orientalizante. Estos matices conectan esta escena con las representaciones plásticas ibéricas que se producirán posteriormente, al soslayar el potencial militar del caballero en favor de su prestigio social y rango económico, evidenciado en su particular atuendo, tocado y en las cuidadas crines y cola de su caballo. ¿Qué mensaje codificaba esta escena? ¿Respondía este mensaje a una sensibilidad particular incipiente en la Península Ibérica? ¿Porqué se empleó esta imagen como marca anfórica precisamente en una época y geografía en la que el sellado de contenedores era todavía algo poco convencional?

\section{FUNCIÓN: ESTO NO ES UN JINETE}

El estampillado de ánforas arcaicas es un hecho bien conocido aunque no demasiado frecuente. Los casos registrados en ánforas fenicias en ámbito peninsular se concentran en yacimientos costeros como Castillo de Doña Blanca con siete ejemplares, Huelva con cuatro, Morro de Mezquitilla (Velez-Málaga) con tres y Cádiz, Carmona (Sevilla), Cerro del Villar (Málaga), Villaricos (Almería), Alt de Benimaquia (Denia, Alicante) o La Moleta del Remei (Alcanar, Tarragona) con un ejemplar cada uno. También hay casos en otros lugares más al interior como en El Monastil (Elda, Alicante) o en Medellín (Badajoz). El fenómeno del sellado de ánforas fue marginal hasta los ss. III-I a.C. excepto en el área de Cartago, donde se documenta un crecimiento de este uso a partir del s. V a.C. (Ramón, 1995, 245-255). En época helenística la práctica de marcar contenedores se popularizó por todo el Mediterráneo, pero ya en un contexto histórico y económico diferentes al arcaico y, por tanto, probablemente con una funcionalidad también distinta.

El marco geográfico del sureste peninsular y, más concretamente, la cuenca del Segura, es una zona privilegiada por el número de hallazgos de este tipo que pueden ser adscritos a los ss. VI-V a.C. (fig. 4). Destacan los 19 casos documentados en Peña Negra (Crevillente, Alicante), tanto en ánforas fenicias importadas como en producciones locales (González y Ruiz, 1991, 62-71) y otros seis en diversos yacimientos de esta cuenca (Mata y Soria, 1997, 307-316). De

1993) y en la posterior evolución durante los periodos geométrico y arcaico del simbolismo asociado a este animal (Domínguez, 2005, 211-216).

11 Recordemos que tan sólo en el $5 \%$ de los ajuares funerarios ibéricos excavados se han encontrado arreos, lo que indica el carácter exclusivo y restringido de la posesión de caballos en estas sociedades (Quesada, 1998, 174-176). 
las inmediaciones de El Macalón se pueden añadir otros cuatro casos, además de los ocho ejemplos procedentes de El Castellón (Hellín, Albacete) (Soria y Córdoba, 1994), varios de Los Almadenes (Hellín, Albacete) (Sala y López, 2000) y siete más de Los Molinicos $^{12}$ (Moratalla, Murcia) (Mata y Soria, 1997, 308).

La cantidad de ánforas fenicias e ibéricas selladas en estas cronologías antiguas es relativamente escasa comparado con la posterior evolución que protagonizará la producción anfórica en el Mediterráneo de época helenística. Pese a ello, la variedad tipológica de las marcas arcaicas es muy amplia. Existen muchos registros únicos y tan sólo se encuentran repetidos los sellos más simples, e.g. cruciformes o rosetas ( $c f$. Mata y Soria, 1997). Ello invita a descartar que estas marcas hagan referencia a productos concretos contenidos en el interior del envase, pues su variedad difícilmente pudo ser tan amplia. Tampoco podría tratarse de una identificación de las localidades de producción o destino de las mercancías, pues también habrían sido halladas más repeticiones. Más verosímil resulta en cambio que dichas marcas hagan referencia a los agentes sociales implicados en la producción, distribución y/o consumo. Son marcas claramente diferentes a los estampillados de tipo Valdepeñas (Esteban, 2000) que, con finalidad decorativa, se aplicaron en el Vaso de los
Dragones de la Hoya de Santa Ana, Albacete (Blánquez, 1990, 302-303) o en vasos de cerámica a mano del depósito A de Castrejón de Capote, Badajoz (Berrocal, 1989, 277).

El sellado de ánforas en esta cronología estaría, por tanto, encaminado a establecer algún tipo de control sobre fases de producción, transporte o consumo del ánfora o de su contenido. Se trataría de fases que, en principio y sin las marcas, escaparían a dicho control. Se entiende así por qué un objeto relativamente voluminoso, como es el ánfora, viene identificado mediante marcas tan pequeñas, frecuentemente simples y poco llamativas, hasta el punto de poder pasar desapercibidas para un observador situado a varios metros del ánfora. No son marcas destinadas a la visualización de cualquiera, sino especialmente dedicadas a quienes las manipulan. Probablemente por ese motivo las marcas se encuentran habitualmente junto al asa, es decir, allí en donde no pueden pasar desapercibidas para quien las asga. Son, pues, un indicio de la existencia de elementos sociales (personas, familias o instituciones) con aspiraciones a ejercer un dominio creciente sobre la circulación de los bienes de prestigio transportados.

Es cierto que el contenido de las ánforas marcadas no ha podido determinarse en cada caso. Si bien su morfología parece destinada a contener líquidos, tampoco puede descartarse otro tipo de bienes, como fru-

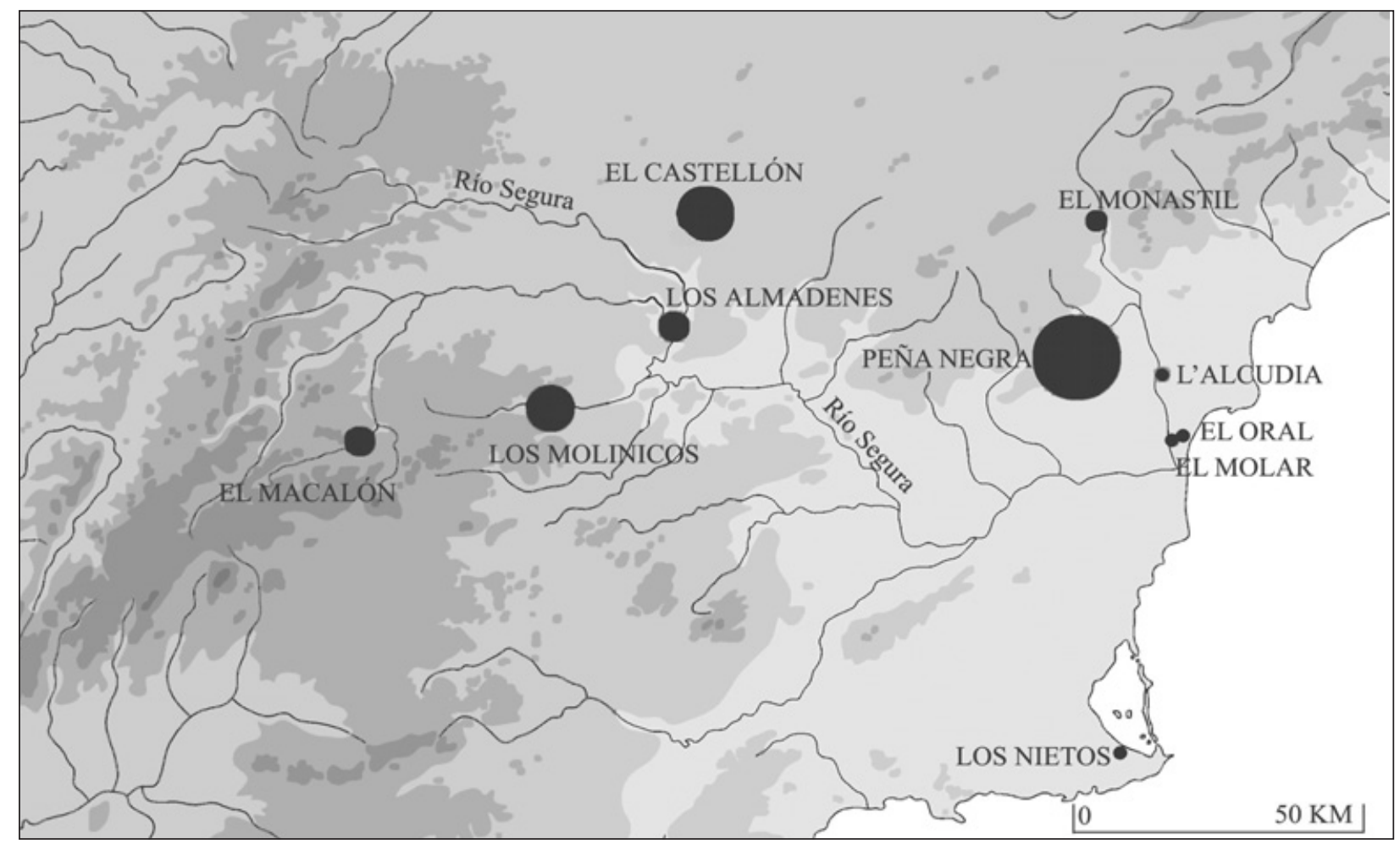

Figura 4. Mapa de distribución de los hallazgos de marcas en ánforas entre los ss. VII-V a.C. Elaboración propia a partir de Mata Parreño y Soria Combadiera (1997).

12 Yacimientos situados a 60, 45 y $25 \mathrm{Km}$ de distancia de El Macalón, respectivamente. 
tos secos. Los contenidos más plausibles en estas cronologías son vino u otras bebidas alcohólicas, así como salazones de pescado o aceites. En cualquier caso se trataría, especialmente para las ánforas selladas, de contenidos relevantes y merecedores de una atención especial.

Desde esta perspectiva cobra mayor interés aún la estampilla amortizada en El Macalón, producto de un tampón improvisado y con cualidades estéticas mucho más llamativas que las del resto de marcas documentadas en la cuenca del Segura. No podemos saber si este sello identificaba a la autoridad establecida en El Macalón, o a los responsables de la producción de valiosos bienes en otras geografías, a poderes que aspirasen a controlar la producción del envase o el comercio y/o el consumo del contenido. Lo que sí se puede afirmar es, en mi opinión, que el mensaje criptografiado en la estampilla de El Macalón responde a una estrategia de comunicación inexistente anteriormente.

La práctica del sellado ya era conocida cuando se produjo esta marca, pero este tipo figurado representando a un personaje de rango económico y social elevado supuso una propuesta nueva en la cuenca del Segura. Cabe relacionar dicha propuesta, curiosa y atractiva, con el intento de transmitir una información también novedosa, fruto de las nuevas expectativas, intereses y ambiciones propias de un contexto en pleno proceso de transformación. Aunque hasta ahora no había sido percibido así por los especialistas del mundo ibérico, el sello que nos ocupa es la evidencia arqueológica del uso de (nuevos) instrumentos al servicio de la reproducción y promoción del estatus socioeconómico de la aristocracia ibérica de finales del s. VI a.C.

El caballero de El Macalón, como la pipa de Magritte, es, sobretodo, un acto de comunicación. En él se convierte al jinete aristocrático en símbolo y, contemporáneamente, se funden sus atributos con los del ánfora y/o su contenido. Y todo ello en el afán último de incrementar el control sobre la producción, circulación o consumo de determinados bienes de prestigio. El caballero de El Macalón es, por ello, mucho más que la simple imagen de un jinete: es la materialización de un discurso de poder, en el sentido foucaultiano del término.

\section{Conclusión}

En este artículo se ha revisado una marca anfórica amortizada en un contexto de finales del s. VI o de principios del s. V a.C. en El Macalón, recuperada en excavaciones antiguas y depositada en el Museo de Albacete. El ánfora pudo contener un bien preciado y fue custodiada en lo que pudo ser un almacén situado en proximidad a la muralla del asentamiento. Este ánfora fue fabricada en un lugar por el momento imposible de determinar aunque probablemente ubicado en la costa del sureste peninsular. Luego fue estampillada antes de su cocción con un objeto metálico, que no fue creado a tal efecto, cuya decoración reunía motivos y estilos varios, eclécticos, propios del Mediterráneo globalizado de las élites orientalizantes, pero en una combinación particular e innovadora que se revelaría de éxito entre las aristocracias locales del sureste peninsular durante las décadas y siglos siguientes: estéticamente ligada a la tradición artesanal fenicia pero con elementos de otros ámbitos culturales y temáticamente diferente, al distanciarse de los jinetes fenicio-púnicos al galope. La imagen que decoraba este objeto parece ser un collage de elementos preexistentes, globales, seleccionados para una sensibilidad particular y local.

El acto de aplicar este objeto metálico en altorrelieve sobre el barro fresco de un ánfora supone a su vez un segundo elemento innovador. Por supuesto, las prácticas sociales relacionadas con el prestigio de las elites, en los que la estética y los usos de las aristocracias fenicias ejercen un papel preponderante, son, ya desde el s. VIII a.C., una constante en el área mediterránea de la Península Ibérica. Sin embargo, lo singular del ejemplo aquí analizado es que también en una geografía alejada $150 \mathrm{~km}$ de la costa se evidencian nuevas necesidades socioeconómicas que no pudieron ser cubiertas mediante los medios que aquellas comunidades habían tenido hasta la fecha a su disposición. El intento de cubrirlas fue lo que propició la adopción de nuevas estrategias de comunicación. El caballero de El Macalón puede ser interpretado, en este sentido, como una prueba de esas innovaciones. Todo ello pone de manifiesto la existencia de importantes transformaciones políticas en la región del Nerpio durante el s. VI a.C. Es interesante resaltar que éstas, aunque apuntaban directamente a la formación de la ciudad ibérica, tanto en sentido arquitectónico como político, no cristalizaron en El Macalón en un proyecto urbano duradero, como en cambio sí sucedió en otros yacimientos del entorno, e.g. Peñarrubia (Elche de la Sierra, Albacete).

Quedan abiertas muchas interesantes cuestiones sobre la funcionalidad práctica general del acto de sellar ánforas: identificaba el sello al consumidor o al productor? al responsable del bien envasado o del envase? anunciaba una marca la excelencia del contenido o aspiraba a disfrazar ante un destinatario inexperto una calidad o procedencia mediocres? La respuesta a dichas preguntas no puede partir del examen de una única marca, por excepcional que esta sea. Lo que el sello de El Macalón sí nos indica es la existencia allí durante el Hierro Antiguo de transformaciones sociopolíticas acompañadas de intentos de canalizarlas mediante estrategias de comunicación innovadoras y sofisticadas.

Destacar la importancia de este yacimiento para la Protohistoria del sureste peninsular no es ninguna novedad. Sin embargo, con este estudio de detalle se llama la atención sobre los procesos de creciente diferenciación social, incipiente urbanización y emergen- 
cia aristocrática acaecidos entre las sociedades de esta región entre los ss. VI-V a.C. Estos procesos anticiparon la consolidación demográfica y política del hábitat nuclear y, por tanto, se hallan en la base del nacimiento de las ciudades ibéricas y de las formas estatales de gobierno. Está aceptado que las trayectorias de formación seguidas por estas sociedades protohistóricas fueron complejas y heterogéneas, y que la consolidación de la vida urbana no siguió en todas las regiones peninsulares los mismos ritmos. Su estudio, por tanto, requiere superar el desequilibrio geográfico persistente en la arqueología ibérica en favor de las áreas costeras y atender algo más a los territorios interiores.

\section{Bibliografía}

Abad Casal, L., Sala Sellés, F. y Sánchez de Prado, Mª . D. (1993): Materiales ibéricos y romanos del poblado de El Alberri (Cocentaina) conservados en la colección del Centre d'Estudis Contestans. Alberri 6, 47-73.

Adroher Auroux, A. M. (2008): La Bastetania arqueológica. Estado de la cuestión. En: Adroher Auroux, A. M. - Blánquez Pérez, J. (eds.) I Congreso Internacional de Arqueología Ibérica Bastetana, Serie Varia 9, Universidad Autónoma de Madrid, Madrid, 211-246.

Alfaro Asins, C. (1986): Sistematización del antiguo numerario gaditano. En: del Olmo Lete, G. - Aubet Semmler, M. E. (eds.) Los fenicios en la Península Ibérica, II, Ausa, 121-137, Barcelona.

Almagro Basch, A. (1975): Las raíces del arte ibérico. Papeles del Laboratorio de Arqueología 11, 251279.

Almagro Gorbea, M. J. (1986): Orfebrería feniciopúnica del Museo Arqueológico Nacional, Museo Arqueológico Nacional, Madrid.

Almagro-Gorbea, M. (2004): Una pátera fenicia de Nubia y el comercio fenicio en los confines del Mundo Antiguo. Complutum 15, 7-32.

Almagro-Gorbea, M. (2005): Ideología ecuestre en la Hispania prerromana. Gladius 25, 151-186.

Aranegui Gascó, C. (1997): La decoración figurada en la cerámica de Llíria. En: Aranegui Gascó, C. Mata Parreño, C. - Pérez Ballester, P. (eds.) Damas y caballeros en la ciudad ibérica. Las cerámicas decoradas de Llíria (Valencia), Cátedra, Madrid, 49-116.

Astruc, M. (1959): Empreintes et reliefs carthaginois de terre cuite. Mélanges de l'École Française de Rome - Antiquité 71, 107-134.

Aubet Semmler, M. E. (1978): Los marfiles fenicios del Bajo Guadalquivir, I: Cruz del Negro. Boletín del Semanario de Estudios de Arte y Arquelogía 44, 15-88.

Aubet Semmler, M. E. (1980): Los marfiles fenicios del Bajo Guadalquivir, II: Acebuchal y Alcantarilla.
Boletín del Semanario de Estudios de Arte y Arquelogía 46, 33-92.

Aubet Semmler, M. E. (1982): Los marfiles fenicios del Bajo Guadalquivir, III: Bencarrón, Santa Lucía y Setefilla. Pyrenae 17-18, 231-280.

Bär, J. (1996): Der assyrische Tribut und seine Darstellung: eine Untersuchung zur imperialen Ideologie im neuassyrischen Reich, Neukirchener Verlag, Kevelaer.

Bénichou-Safar, H. (2007): Iconologie générale et iconographie carthaginoise. Antiquités africaines 43, 5-46.

Berrocal-Rangel, L. (2007): El asentamiento "céltico" del Castrejón de Capote (Higuera la Real, Badajoz). CUPAUAM 16, 245-295.

Bisi, A. M. (1968): I pettini d'avorio di Cartagine. Africa 2, 11-74.

Blánquez Pérez, J. (1990): La formación del mundo ibérico en el sureste de la Meseta. Estudio arqueológico de las necrópolis ibéricas de la provincia de Albacete, Instituto de Estudios Albacetenses, Albacete.

Blánquez Pérez, J. (1996): Caballeros y aristócratas del s. V a.C. en el mundo ibérico. En: Olmos Romera, R. - Santos Velasco, J. (eds.) Iconografía ibérica, iconografía itálica. Propuestas de interpretación y lectura, (Roma, Noviembre 1993), Universidad Autónoma de Madrid, Madrid, 211-234.

Blech, M. y Ruano, E. (1999): Un posible taller de esculturas ibéricas en el poblado fortificado de El Macalón, El Nerpio, Albacete. Actas del XXV Congreso Nacional de Arqueología, (Valencia, 2427 de Febrero 1999), 594-599.

Blinkemberg, Chr. (1926): Fibules grecques et orientales, Andr. Fred. Host \& Son, Copenhage.

Boardman, J. (2003): Classical Phoenician Scarabs. A catalogue and study, BAR Int. Series 1190, Oxford.

Bonet Rosado, H. (1995): El Tossal de Sant Miquel de Llíria, Diputación de Valencia, Valencia.

Bonet Rosado, H. y Mata Parreño, C. (2008): Las cerámicas ibéricas. Estado de la cuestión. En: Bernal Casasola, D. - Ribera i Lacomba, A. (eds.) Cerámicas hispanorromanas. Un estado de la cuestión, Universidad de Cádiz, Cádiz, 147-170.

Cela Espín, X. (2006): Las cerámicas ibéricas del periodo Ibérico Antiguo (siglos VI-V a.C.): estado de la cuestión y propuestas. En: Belarte, C. Sanmartí, J. (eds.) De les comunitats locals als estats arcaics: la formació de les societats complexes a la costa del Mediterrani occidental, (Calafell, noviembre 2004). Arqueo Mediterrànea 9, Universitat de Barcelona - Institut Català d'Arqueologia Clàssica 
Chapa Brunet, T. (1985): La escultura ibérica zoomor$f a$, Ministerio de Cultura, Madrid.

Chapa Brunet, T. (2009): Las esculturas ibéricas de El Álamo-Jutia (Yeste-Nerpio, Albacete). Homenaje a Michel Blech, Boletín de la Asociación Española de Arqueología 45, 79-93.

Cintas, P. (1951): Deux campagnes de foulles à Utique. Karthago 2, 3-88.

Cruz Andreotti, G. (2003): La construcción de los espacios políticos ibéricos entre los ss. III-I a.C. Algunas cuestiones metodológicas e históricas a partir de Polibio y Estrabón. Cuadernos de Prehistoria y Arqueología de la Universidad Autónoma de Madrid 28-29, 35-54.

Cruz Andreotti, G., Le Roux, P. y Moret, P. (eds.) (2006-2007): La invención de una geografía de la Península Ibérica, Casa Velázquez, MadridMálaga. 2 vols.

De la Bandera Romero, M. L. (2010): La joyería fenicio-púnica: una valoración técnica y social: el marco de la Península Ibérica e Ibiza. En: Costa, B. - Fernández, J. (eds.) Aspectos suntuarios del mundo fenicio-púnico en la Península Ibérica, XXIV Jornadas de Arqueología FenicioPúnica, (Ibiza 2009), Ibiza, 47-75.

Domínguez Monedero, A. J. (2005): Jinetes en Grecia y sus ecos en la cultura ibérica. Gladius 25, 207-236.

Drews, R. (2004): Early riders. The beginnings of mounted warfare in Asia and Europe, Routledge, Londres.

Esteban Borrajo, G. (2000): Una característica producción cerámica pintada del periodo ibérico pleno en el sur de la meseta. Cuadernos de Prehistoria y Arqueología de la Universidad Autónoma de Madrid 26, 69-84.

Fernández Gómez, J. y Padró Parcerisa, J. (1982): Escarabeos del Museo Arqueológico de Ibiza, Ministerio de Cultura, Madrid.

Freyer-Schauenburg, B. (1966): Elfenbeine aus dem samischen Heraion: Figürliches, Gefäße und Siegel, Cram, Hamburgo.

Gabrielli, M. (2006): Le cheval dans l'empire achéménide. Ege Yayinlari, Estambul.

García Guinea, M. A. (1960): Excavaciones y estratigrafías en el poblado ibérico de El Macalón (Nerpio, Albacete). Revista de Archivos, Bibliotecas y Museos 68 (2), 709-755.

García Guinea, M. A. - San Miguel Ruiz, J. A. (1964): Poblado ibérico de El Macalón (Albacete). Excavaciones Arqueológicas en España 25, Madrid.

González Prats, A. (1986): Las importaciones y la presencia fenicias en la sierra de Crevillente (Alicante). En: Del Olmo Lete, G. - Aubet Semmler, M. E. (eds.) Los fenicios en la Península Ibérica, Ausa, Barcelona, 279-302.
González Prats, A. y Ruiz Segura, E. (1991): Nuevos datos sobre urbanística y cultura material en el Hierro Antiguo del Sudeste (Peña Negra, 1986). Lucentum 9-10, 51-75.

Izquierdo Praile, I. (2000): Monumentos funerarios ibéricos: los pilares-estela, Trabajos Varios del SIP 98, Diputación de Valencia, Valencia.

Jiménez Ávila, J. (2002): La toréutica orientalizante en la Península Ibérica, Real Academia de la Historia, Madrid.

Keel, O. (1995): Corpus der Stempelsiegel-Amulette aus Palästina/Israel. Von den Anfängen bis zur Perserzeit, Orbis Biblicus et orientalis 10, Göttingen.

Keel, O. (2010): Corpus der Stempelsiegel-Amulette aus Palästina/Israel. Von den Anfängen bis zur Perserzeit, 2, Orbis Biblicus et orientalis 29, Göttingen.

Kellner, H-J. (1991): Gürtelbleche aus Urartu, Prähistorische Bronzefunde 12, 3. Stuttgart.

Kilian, K. (1975): Fibeln in Thessalien von der mykenischen bis zur archaischen Zeit, Prähistorische Bronzefunde 14, 2. München.

Kilian-Dirlmeier, I. (1979): Anhänger in Griechenland von der mykenischen bis zur spätgeometrischen Zeit, Prähistorische Bronzefunde 11, 2. München.

Kourou, N. (2008): The evidence from the Aegean. En: Sagona, C. (ed.) Beyond the homeland: markers in Phoenician chronology, Peeters, Leuven, 305-364.

Lo Schiavo, F. (2010): Le fibule dell'Italia meridionale e della Sicilia dall'età del Bronzo recente al VI secolo a.C., Prähistorische Bronzefunde 14, 14. Stuttgart. 3 vols.

Lubtchansky, N. (2005): Le cavalier tyrrhénien: représentations équestres dans l'Italie archaïque, École Française de Rome, Roma.

Marín Ceballos, M. C. (1980): Documentos para el estudio de la religión fenicio-púnica en la Península Ibérica, II. Deidades masculinas. Habis 10-11, 217-232.

Martín de la Cruz, J. C. (2003): La época orientalizante en la actual provincia de Córdoba. En: Blánquez Pérez, J. (ed.) Cerámicas orientalizantes del Museo de Cabra. Ayuntamiento de Cabra, 55-77.

Martos Quesada, J. (2009): Los Reinos de Taifas en el s. XI. Historia de España Medieval. AlAndalus, Istmo, Madrid, 147-272.

Mata Parreño, C. y Soria Combadiera, L. (1997): Marcas y epígrafes sobre contenedores de época ibérica. Archivo de Prehistoria Levantina 22, 297-360. 
Matthiae, P. (1999 [1998]): Ninive. Glanzvolle Hauptstadt Assyriens. Hirmer, München.

Mederos Martín, A. y Ruiz Cabrero, L. A. (2004): El pecio fenicio del Bajo de la Campana (Murcia, España) y el comercio del marfil norteafricano. Zephyrus 57, 263-281.

Mitchell, T. C. y Searight, A. (2008): Catalogue of the Western Asiatic Seals in the British Museum. Stamp seals III: Impressions of stamps seals on cuneiform tablets, clay bullae and jar handles, Brill, Leiden.

Molina Fajardo, F. (1986): Almuñécar a la luz de los nuevos hallazgos fenicios. En: Del Olmo Lete, G. - Aubet Semmler, M. E. (eds.) Los fenicios en la Península Ibérica, Ausa, Barcelona, 193-216.

Moore, M. B. (1972): Horses on black-figured Greek vases of the Archaic Period (620-480 BC), Ann Arbor, Michigan.

Nunn, A. (2000): Der figürliche Motivschatz Phöniziens, Syriens und Transjordaniens vom 6. bis zum 4. Jahrhundert v. Chr., Orbis Biblicus et orientalis 18 , Göttingen.

Onasoglou, A. (1981): Oi geometrikoí táphoi tes Tragánas sten anatoliké Lokrída, Archaiologikón Deltion 36-1, 1-57.

Parrot, A., Chébab, M. H. y Moscati, S. (2005 [1975]): Fenici. Il Mediterraneo prima di Roma, Corriere della Sera, Roma.

Pedrizet, P. (1908): Fouilles de Delphes, 5. Monuments figurés, petits bronzes, terres-cuites, antiquités diverses, Paris.

Pellicer Catalán, M. (1999): El poblamiento de El Macalón de Nerpio (Albacete) en el contexto protohistórico del Sureste hispano. Estudios en homenaje al profesor Dr. García Guinea, Comunidad de Castilla-La Mancha, Albacete, 281-288.

Perea Caveda, A. (1991): Orfebrería prerromana. Arqueología del oro, Comunidad de Madrid, Madrid.

Philipp, H. (1981): Bronzeschmuck aus Olympia, Olympische Forschungen 13, Walter de Gruyter, Berlin.

Pingel, V. (1992): Die vorgeschichtlichen Goldfunde der iberischen Halbinsel. Eine archäologische Untersuchung zur Auswertung der Spektralanalysen, Madrider Forschungen 17. Walter de Gruyter, Berlín.

Pisano, G. (1996): L'iconografia del cavaliere nella glittica punica. En: Acquaro, E. (ed.) Alle soglie della classicità. Il Mediterraneo tra tradizione e innovazione. Studi in onore di Sabatino Moscati, Editoriali e Poligrafi Internazionali, Pisa, 917-924.

Plácido Suárez, D. (2009): Hispania Antigua, CríticaMarcial Pons, Madrid.
Popham, M. R. (et al.) (1993): Lefkandi II: the protogeometric building at Toumba. The excavation, architecture and finds, British School of Archaeology at Athens, Atenas.

Quattrocchi Pisano, G. (1974): I gioielli fenici di Tharros nel Museo Nazionale di Cagliari, CNR, Roma.

Quesada Sanz, F. (1997): Jinetes o caballeros? En torno el empleo del caballo en la Edad del Hierro Peninsular. En: García Castro, J. A. - Antona del Val, V. - Azue Brea, L. (eds.) La Guerra en la Antigüedad. Una aproximación al origen de los ejércitos en Hispania, Catálogo de la exposición, Ministerio de Defensa - Ministerio de Cultura, Madrid, 185-194.

Quesada Sanz, F. (1998): Aristócratas a caballo y la existencia de una verdadera caballería en la cultura ibérica: dos ámbitos conceptuales diferentes. En: Aranegui Gascó, C. (ed.) Los iberos. Príncipes de Occidente. Estructuras de poder en la sociedad ibérica, Saguntum Extra-1, Valencia, 169-183.

Ramón Torres, J. (1995): Las ánforas fenicio-púnicas del Mediterráneo central y occidental, Instrumenta 2, Universidad de Barcelona, Barcelona.

Ribichini, S. (2004): Tophet und das punische Kinderopfer. En: Peters, S. (ed.) Hannibal ad portas. Macht und Reichtums Karthago, Catálogo de la exposición en Karlsruhe, Theiss, Karlsruhe, 247-261.

Ruiz Rodríguez, A., Bellón Ruiz, J. P. y Sánchez Vizcaíno, A. (2008): La construction archéologique des Ibères. Entre Orient et Occident. Construire le temps. Histoire et méthodes des chronologies et calendriers des demiers millénaires avant notre ère en Europe occidental, Actas del Colloqui Internacional, (Lillle, diciembre 2006), 307-323.

Ruiz Rodríguez, A. y Molinos Molinos, M. (2009): Identidad y territorio entre los iberos del Alto Guadalquivir. En: Wulf Alonso, F. - Álvarez MartíAguilar, M. (eds.) Identidades, culturas y territorios en la Andalucía prerromana, Universidad de Málaga, Málaga, 133-164.

Sala Sellés, F. y López Precioso, J. (2000): Los Almadenes (Hellín, Albacete). Un poblado orientalizante en la desembocadura del río Mundo. $I V$ Congreso Internacional de Estudios Fenicios y Púnicos, (Cádiz, octubre 1995), Cádiz, 1885-1890.

Sanz Gamo, R. y Blánquez Pérez, J. (2011): Caballeros ibéricos en torno a la Vía Hercúlea. Una mirada sobre la escultura ibérica. En: Bueno, P. - Gilman, A. - Martín Morales, C. - SánchezPalencia, J. (eds.) Arqueología, sociedad, territorio y paisaje. Estudios sobre Prehistoria Reciente, Protohistoria y transición al mundo romano en Homenaje a $M^{a}$ Dolores Fernández Posse, CSIC, Madrid, 253-278. 
Sapouna-Sakellarakis, E. (1978): Die Fibeln der griechischen Inslen, Prähistorische Bronzefunde 14, 4. München.

Soria Combadiera, L. y Córdoba Estepa, Mª (1994): Análisis mineralógicos de piezas cerámicas ibéricas procedentes de "El Castellón" (HellínAlbatana-Albacete). Al-Basit 35, 5-49.

Soria Combadiera, L. (1999): El poblado protohistórico de El Macalón (Nerpio, Albacete). Nuevas aportaciones a la luz de últimas investigaciones. Sautuola 6, 289-296.

Soria Combadiera, L. (2000): La cultura ibérica en la provincia de Albacete. Génesis y evolución a través del estudio del poblamiento, Universidad de Castilla-La Mancha, Cuenca.
Torelli, M. (1997): Il rango, il rito e l'immagine: alle origini della rappresentazione storica romana, Electa, Milano.

Velázquez Brieva, F. (2007): Los amuletos púnicos y su función mágico-religiosa, Costa, B. - Fernández, J. H. (eds.) Magia y superstición en el mundo fenicio-púnico, XXI Jornadas de Arqueología FenicioPúnica, (Ibiza 2006), 97-143.

Vendrell Betí, A. (2010): Rituals i aixovars funeraris al Puig des Molins (Eivissa) al s. VI a.e. El cas d'un olpe de bucchero nero inèdit. En: Mata Parreño, C. - Pérez Jordà, G. - Vives-Ferrándiz Sánchis, J. (eds.) De la cuina a la taula, Saguntum, Extra-9, 333-340. 
